\title{
A reprodução da ideologia da supremacia masculina na divisão sexual do trabalho, na literatura para crianças.
}

- The reproduction of the ideology of male supremacy in the sexual division of work, in the literature for children.

- La reproducción de la ideología de la supremacía masculina en la división sexual del trabajo, en la literatura para niños.

Áurea de Carvalho Costa'

Jaqueline Moreira Ferraz de Lima²

Resumo: Com o intuito de colaborar para o debate sobre a temática da exploração, combinada com a opressão de gênero sobre as mulheres, no âmbito do materialismo histórico e dialético, propusemo-nos a analisar o conteúdo de três livros dos acervos do PNAIC: João e o pé de feijão; Nossa rua tem um problema e As mil e uma histórias de Manoela. Nosso objetivo foi identificar como são retratadas as profissões, as múltiplas jornadas, o trabalho doméstico e a participação das mulheres no sustento familiar, com vistas a contribuir

1 Doutora em Educação pela UNICAMP. Possui pós-doutorado em Trabalho e Educação, com estágio de pesquisa na Facoltà di Sociologia na Universidade Federico II, em Nápoles. É docente do Depto de Educação e do Programa de pós-graduação em educação da UNESP/Rio Claro-SP. aurea.costa@unesp.br

2 Mestra em Educação Pela UNESP / Rio Claro- SP. É professora de Educação Infantil na rede pública de Piracicaba-SP. jaquercjn2@gmail.com 
com o debate para responder à problematização: quais textos apresentariam uma abordagem que contribui para a reprodução da ideologia da supremacia masculina, na vida pública e privada? Os recortes privilegiaram uma análise da potencialidade dessas obras para auxiliar na formação das crianças para a igualdade de direitos entre os gêneros. Portanto, delimitamo-nos das abordagens referentes às teorias literárias, na medida em que nos interessa apresentar elaborações, de aspectos sociológicos, do conteúdo das de tais obras. O debate sobre igualdade de direitos, no âmbito das especificidades das mulheres, ainda não faz parte nem das bases comuns curriculares, nem dos documentos oficiais, que têm orientado os currículos. Evidenciamos que as obras de literatura para crianças, que tocam na questão do trabalho feminino, frequentemente reproduzem padrões de comportamento supremacistas masculinos e fixam a mulher no papel social de cuidadora e protetora, reclusa ao ambiente doméstico, em contradição com os requisitos do capital, que desde o início da industrialização, tem derrubado todas as barreiras de idade, sexo, condições de saúde para intensificar a exploração do trabalho.

Palavras-chave: Direitos das mulheres. Literatura infantil. Trabalho feminino

Resumen: Con la finalidad de colaborar en el debate relacionado al tema de la explotación femenina mezclada con la opresión de género, en el ámbito del materialismo histórico y dialéctico, nos proponemos a analizar tres libros de los acervos del PNAIC: João e o pé de feijão; Nossa rua tem um problema e As mil e uma histórias de Manoela. El objetivo fue identificar como son descritas las profesiones, las múltiples jornadas, el trabajo doméstico y la participación de las mujeres en el sustento familiar, con la finalidad de contribuir con respuestas a la problemática: ¿Cuáles son los textos que abordan y contribuyen a la reproducción de la ideología de la supremacía masculina en la vida pública y privada? Los recortes privilegiaron un análisis sobre la potencialidad de las obras literarias que auxilien en la formación infantil con igualdad de derecho entre géneros. Por lo tanto, los enfoques fueron limitados con referencia a las teorías literarias en la medida que nos interesa presentar los aspectos sociológicos elaborados a través del contenido de las obras. El debate sobre la igualdad de los derechos en el ámbito de las especificidades de las mujeres ni siquiera forman parte de las bases comunes curriculares, ni de los documentos oficiales que han orientado los currículos. Evidenciamos que las obras literarias infantiles que abordan los temas relacionados al trabajo femenino son poco comunes, es frecuente la reproducción sobre los patrones de comportamiento sobre la supremacía masculina e proyectan a la mujer en el 
papel social de cuidadora y protectora reclusa al ambiente doméstico, contradiciendo los requisitos del capital, que desde el inicio de la industrialización han derrumbado todas las barreras, como la edad, sexo, condiciones de salud, para intensificar la explotación del trabajo.

Palabras clave: Derecho de las mujeres. Literatura infantil. Trabajo femenino.

\begin{abstract}
To contribute with them discussion about the theme of exploitation combined with gender oppression of women, under an historic and dialectic materialist point of view, we propose to analyze the content of three books from PNAIC's (National Pact for Literacy at the Right Age): Jack and the beanstalk; Our street has a problem and The thousand and one stories of Manuela. Our aim was to identify how the professions, the multiple journeys, the housework, and the participation of women in the family are portrayed, to contribute to answer to the problematic: which texts would present an approach that contributes to the reproduction of the ideology of male supremacy in public and private life? The selection of these stories had privileged an analysis of the potential of literary works to assist in the training of children for equal rights between genders. Therefore, we limited ourselves to approaches referring to literary theories, insofar as we are interested in presenting elaborations of sociological aspects of the content of the works. The discussion about equal rights in the context of the specificities of women is still not part of the common curriculum bases nor of the official documents that have guided the curricula. We show that the literature works for children that touch on the issue of female labor are not so common, moreover, they frequently reproduce male supremacist behavior patterns and fix women in the social role of caregiver and protector, reclusive to the domestic environment, in contradiction with the requirements of capitalism, that since the beginning of industrialization, it has broken down all barriers of age, sex, and health conditions to intensify the of work.
\end{abstract}

Keywords: Woman's rights. Children's literature. Women's work 


\section{Introdução}

Neste artigo, buscamos abordar a temática da exploração, combinada com a opressão de gênero, sobre as mulheres, a partir da análise do conteúdo da versão mais atualizada de três dos livros dos acervos do Programa Nacional pela Alfabetização na Idade Certa (PNAIC) (BRASIL, 2017), destinados ao segundo e terceiro ano do Ensino Fundamental: João e o pé de feijão (VIANA, 2017); Nossa rua tem um problema (AZEVEDO, 2017); As mil e uma histórias de Manoela (MALUF, 2013).

De acordo com o compromisso firmado entre os estados, municípios e o PNAIC, a alfabetização das crianças deve ser garantida até os oito anos de idade. Por isso, os livros vão se tornando mais complexos para as crianças quanto à extensão do texto, ao enriquecimento do vocabulário e à apresentação de novos gêneros textuais. Após considerar tais aspectos, selecionamos um conto de fadas, um diário e uma narração com elementos de realismo fantástico, dentre a totalidade de obras do acervo do PNAIC, pela riqueza de elementos referentes à discussão sobre gênero e pela frequência das personagens femininas na cena. As três obras foram selecionadas, após a pré-análise do conteúdo de 34 obras com menções ao trabalho feminino, disponibilizadas pelo programa.

Ao constatarmos em estudos anteriores (LIMA, 2019) que as obras de literatura para crianças edificam-se sobre uma estrutura formal coerente e possuem uma introdução, problematização, catarse e desfecho intencional, adotamos os pressupostos que além dos livros conterem didáticas e ideologia, a literatura pode contribuir para a formação humana emancipadora dos alunos na escola (MORTATTI, 2014), pois, como afirma Candido (2011, p. 179) "[...] o caráter de coisa organizada da obra literária torna-se um fator que nos deixa mais capazes de ordenar a nossa própria mente e sentimentos, e, em consequência, mais capazes de organizar a visão que temos do mundo".

Estabelecemos, então, como objetivo identificar, nas três obras escolhidas, o modo como são retratadas as profissões, as múltiplas jornadas, o trabalho doméstico e a participação das mulheres no sustento familiar. Assim, visamos enriquecer o debate acerca da problematização: quais textos apresentariam uma abordagem reprodutora da ideologia da supremacia masculina e quais apresentam figuras femininas e masculinas, em relações igualitárias de gênero no trabalho, na vida pública e na vida privada?

Os recortes do presente artigo privilegiaram uma análise da potencialidade das obras literárias no auxílio à formação das crianças para a igualdade de direitos entre os gêneros. Portanto, delimitamo-nos das abordagens referentes às teorias literárias, pois nos interessa apresentar elaborações de aspectos sociológicos do conteúdo de três obras da literatura, produzidas para 
crianças, indexadas no acervo do PNAIC. No entanto, não abstrairmos que "[...] o conteúdo só atua por causa da forma, e a forma traz em si, virtualmente, uma capacidade de humanizar devido à coerência mental que pressupõe e que sugere" (CANDIDO, 2011, p. 180).

Compreendemos a divisão sexual do trabalho como um complexo resultante de múltiplas determinações, das quais escolhemos apenas algumas, para fins de análise das três obras literárias.

Inicialmente, apresentaremos as principais ideias referentes ao debate acadêmico sobre quatro aspectos da divisão sexual do trabalho escolhidas como guias para a nossa análise dos enredos. Em seguida, analisamos, separadamente, cada uma das três narrativas.

\section{As profissões, as múltiplas jornadas, o trabalho doméstico e o provimento familiar}

À luz do materialismo histórico e dialético, partimos do pressuposto de que esses quatro aspectos referentes à divisão sexual do trabalho não podem ser analisados separadamente, senão para fins didáticos, pois formam uma totalidade complexa, sendo produto de relações sociais em sociedades de classes, regidas pela propriedade privada (ENGELS, 1977).

Trata-se de um complexo rico em contradições, as quais têm servido, na atualidade, ao aprofundamento de relações de opressão e de exploração do trabalho feminino, cada vez mais intensamente. Isso ratifica a tese de que, para além da articulação entre o trabalho feminino e o masculino, a divisão sexual do trabalho consiste numa relação social, em que o trabalho masculino serve às funções produtivas do capitalismo e o feminino, às reprodutivas (HIRATA, 2012).

O fenômeno da divisão sexual do trabalho tem se tornado uma relação social cada vez mais violenta de subordinação da mulher no mercado de trabalho e no ambiente doméstico, na conjuntura do acirramento da crise do capital e como uma das consequências dele.

As mulheres trabalhadoras e provedoras da família acumulam múltiplas jornadas e, reversamente, tal acúmulo serve como indício de uma hipotética baixa produtividade da mão de obra feminina e, consequentemente, tem justificado discriminações na forma de salários mais baixos, dificuldades maiores para ascensões na carreira. Delineia-se um perverso círculo vicioso e o direito ao trabalho remunerado - com direitos, isonomia salarial, plano de carreira, estabilidade - sofre destituição, especialmente no caso da mão de obra feminina, conforme demonstram alguns estudos empíricos internacionais:

[...] onde há polivalência, revezamento e oportunidades de formação e de carreira, são os trabalhadores do sexo masculino que 
interessam, sendo a execução simples e repetitiva do trabalho reservada às mulheres, e esse trabalho é considerado perfeitamente compatível com suas múltiplas atividades na esfera familiar e doméstica (HIRATA, 2012, p. 43).

A partir das especificidades da condição feminina natural de parturiente, puérpera e nutriz, por extensão, se lhes impõe socialmente a responsabilidade do contínuo cuidado dos filhos e de toda a família. Essa é a matriz da representação feminina da "cuidadora" por natureza.

Dá-se uma naturalização da exploração da representação de mulher responsável única ou principal pela ordem no lar, cujo trabalho doméstico - além de não remunerado - é invisibilizado, embora contribua para a reprodução do capital. Entretanto, as chamadas "donas de casa" garantem as condições básicas do cumprimento das jornadas laborais diárias: alimentação, limpeza, ambiente limpo e seguro para descanso após a jornada.

Como assinalamos anteriormente, para além do trabalho doméstico, a mão de obra feminina se faz presente na produção e na circulação das mercadorias, no trabalho remunerado informal, sujeito à superexploração, tornando, a condição de explorada permanente durante a existência das mulheres:

Enfim, essas pesquisas mostraram que era necessário atentar não apenas para o continuum trabalho assalariado formal/remunerado/ informal/doméstico, mas também para as descontinuidades (alternativas e rupturas entre o assalariamento industrial, o trabalho ocasional, o trabalho informal, ou mesmo a saída do mercado do trabalho e a responsabilidade exclusiva pelo trabalho doméstico (HIRATA, 2012, p. 19).

O fenômeno da exploração do trabalho feminino tem demandado problematizações, por parte da academia e das lutas dos movimentos sociais, e não se restringe ao combate às desigualdades no acesso do direito ao trabalho aos homens e mulheres, mas ao atendimento das especificidades dos direitos delas, decorrentes das especificidades concernentes ao gênero:

Exigir políticas antidiscriminatórias baseadas na igualdade aparente pode ser contraproducente. $\mathrm{O}$ esforço da primeira mulher que atinge um cargo hierárquico que é vista e avaliada por sua capacidade pessoal, mas também como uma representante do gênero feminino e muito maior que o de seus colegas homens e a coloca numa situação de profunda desigualdade. Reconhecer que não existe igualdade implica então aplicar políticas especiais positivas que transformem as condições iniciais de forma a gerar igualdade (JELIN, 1994, p. 144).

Essa reflexão leva-nos a pensar na importância de considerar-se, por exemplo, o fato de as mulheres terem múltiplas jornadas, devido à incipiente educação dos homens, desde a infância, para colaborarem nas tarefas do- 
mésticas e de criação dos filhos.

Quanto ao trabalho fora de casa, há ainda direitos especialmente das mulheres, minimamente reconhecidos pela Consolidação das Leis do TrabaIho, como o direito à amamentação no local de trabalho, à licença gestante de 120 a 180 dias e outros sob disputa entre capital e trabalho.

Na passagem da manufatura para o capitalismo, as mulheres burguesas eram subordinadas e dependentes, até mesmo do ponto de vista econômico. Elas podiam exercer atividades comerciais, porém sempre tuteladas pelo marido ou pai (SAFIOTI, 2013).

As mulheres pobres eram aproveitadas como mão de obra, com preço depreciado, no contexto do capitalismo industrial, o que nos levou a cogitar que compreender isto como uma ampliação do espaço feminino no mercado de trabalho constitui-se numa apreensão aparente do fenômeno, pois, no âmbito da a uma análise da sociedade capitalista como totalidade complexa"[...] a passagem de uma sociedade pré-capitalista para o regime capitalista de produção implica um aproveitamento parcial da mão de obra feminina efetivamente empregada no sistema produtivo anterior". (SAFFIOTI, 2013, p. 331).

Conquanto as funções produtivas das mulheres tendessem a regredir, na passagem do feudalismo para o capitalismo, quando a família deixa de ser a unidade produtiva naquele ambiente rural, "[...] ficam, por assim dizer, divididas as funções domésticas e as funções diretamente econômicas entre os sexos, divisão esta geradora da independência econômica individual [...] em grande escala para o homem e em muito pequena escala para a mulher" (SAFFIOTI, 2013, p. 332).

Tais reflexões sobre a inserção das mulheres no mercado de trabalho não se deram na mesma escala daquela conquistada pelos homens e, na atualidade, o trabalho feminino percorre um continuum entre a formalidade e a informalidade, vida pública e a doméstica. Isso gera a hipótese de que a mulher, no modo de produção capitalista, é transpassada pelo trabalho nas esferas pública e privada, durante toda a vida, nos diferentes contextos do capitalismo e notadamente nas mulheres da classe trabalhadora, isso é motivado pela necessidade de provimento da família, total ou parcialmente (HIRATA, 2021).

A escola é uma das instituições estatais com um enorme potencial para a educação e prevenção à opressão de gênero sobre as mulheres, por isso é tão importante a inserção dessa temática se constitua em conteúdo do currículo; mas a realidade nos mostra que temáticas como trabalho feminino e violência contra a mulher praticamente são inexistentes nos documentos oficiais orientadores da organização curricular do ensino oficial (LIMA, 2019). Apesar dessa ausência, conseguimos identificar na literatura para crianças, um mediador importante para a discussão sobre divisão sexual do trabalho.

Segundo Abrantes (2011), os livros de literatura para crianças reprodu- 
zem os tensionamentos da conjuntura de quando são escritos, na forma como articulam os aspectos cognitivos, éticos, políticos e estéticos nas histórias. Porém, nem todas as obras possuem essa riqueza, "[...] pois existem materiais orientados para o consumo compulsivo, para a promoção do conformismo e para a produção de subjetividades massificadas [...]" (ABRANTES, 2011, p. 235).

A temática da abordagem do trabalho feminino na literatura para crianças é bastante específica. Então, é mais difícil obter uma produção acadêmica robusta. Porém, encontramos as pesquisas existentes sobre representação da mulher são densas e problematizadoras, como a análise da figura das princesas e das fadas nos contos de Marina Colasanti, considerando tanto o patriarcado quanto o feminismo como ideologias (RAMALHO, 2001) e a de Fortunato (2015) sobre a evolução da representação da figura da princesa nos contos de fadas em três contos, escritos em conjunturas diferentes, mediante as transformações nos costumes referentes às mulheres na sociedade capitalista.

Argüello (2005) adotou a perspectiva da análise do discurso foucaultiano, aplicada na leitura crítica dos livros de literatura para crianças; constatou-se a potencialidade das obras para serem apropriadas como "[...] artefato[s] para problematizar as relações de poder entre homens e mulheres e principalmente para desconstruir aqueles mecanismos sutis de produção e legitimação das masculinidades e das feminilidades, no âmbito da cultura (ARGÜELLO, 2005, p. 163).

A leitura desses trabalhos foi profícua para a compreensão de aspectos superestruturais da opressão feminina, embora não se baseiem na premissa básica do feminismo fundamentada no materialismo histórico e dialético, o qual consiste na combinação da opressão com a exploração e não se restringe aos aspectos superestruturais, mas inclui os estruturais - referentes à economia política. Tais questões nos levaram ao estudo de um aspecto estrutural, que impacta na economia política, como o trabalho feminino, dentro da particularidade das relações de gênero, no modo de produção capitalista, vindo a contribuir para a elucidação desta totalidade concreta, da qual nos aproximamos em cada uma das obras infantis escolhidas.

\section{2. "Do lar": a mulher como nutriz e cuidadora na obra João e o pé de feijão}

O livro João e o pé de feijão (VIANA, 2017) pertence ao acervo número três, do PNAIC, destinado ao terceiro ano do Ensino Fundamental. Conforme as metas do PNAIC, os professores, em formação continuada, recebem a atribuição de alfabetizar as crianças até os oito anos. O livro em análise tem uma dupla funcionalidade: constituir-se numa obra com texto relativamente mais extenso em relação àqueles oferecidos às alunas e alunos das séries anterio- 
res e palavras rimadas, portanto, desafiadora, ao explorar amplamente o vocabulário e apresentar o cordel.

O conto João e o pé de feijão foi escrito por Benjamin Tabart (17671833), publicado em 1807, mais popular quando de sua republicação em 1890, por Joseph Jacobs (1854-1916).

Viana (2017) é um autor de cordéis, nascido e alfabetizado no meio rural do sertão cearense, constituindo-se num trabalho original de interlocução entre o cordel e a comunicação de massa. Por isso, suas obras têm sido objeto de estudos e traduções para diversas línguas, de modo a proporcionar discussões sobre a cultura oral nordestina, nas salas de aula, na condição de manifestação literária "[...] rudimentar e advinda de práticas populares e folclóricas, que servem como instrumento de comunicação no âmbito da sociedade nordestina [...]" (JAHN, 2011, p. 117).

As personagens femininas com forma humana são a mãe, a esposa do gigante e a esposa de João. Elas não são evocadas pelos nomes próprios em nenhum momento da história, mas pelo seu papel social, ou pela caracterização física: mãe, esposa ou giganta.

Identificamos na versão de Viana (2017) os enredos de 1807 e 1890, em que um trabalhador pobre luta pela distribuição da riqueza, evocando as lutas dos destituídos organizados em movimentos operários das décadas de 1840 e 1850 , contra os donos dos meios de produção, especialmente, quando da conquista da jornada de 10 horas de trabalhos diários e da proibição do trabalho infantil - ocorrida anteriormente à escrita da versão de Jacobs (MARX, 1998).

Entretanto, a luta entre explorados e exploradores, na versão de Viana (2017) passa a evocar um problema social no cenário rural brasileiro: a apropriação indébita de terras alheias, denominada "grilagem". João, um agricultor pobre que rouba o gigante para restituir a herança de seu avô falecido, Jesuíno, assumindo a luta por um patrimônio, cuja herdeira direta é a mãe.

Em todo o texto a ganância é atribuída aos personagens masculinos, podendo ser interpretada como uma exacerbação do empreendedorismo. $O$ enredo retrata a ganância não só o gigante, mas também João, pois ele não se sacia com os bens que ele subtraiu ao gigante e volta a saqueá-lo mais duas vezes.

A primeira figura feminina a ser apresentada na obra é a mãe de João. Essa família é do tipo família monoparental e pobre; a vaca é o meio de sustento familiar. Com o leite extraído, a mãe produz gêneros alimentícios que são comercializados por João na cidade. "Do leite sua mãe fazia o queijo, a coalhada e a nata e João vendia na feira por quantia bem barata" (VIANA, 2017, p. 4)".

A mãe de João participa do provimento da família, na produção dos gêneros para a comercialização na cidade, e ainda o orienta sobre a venda da vaca. Pode-se extrair do enredo uma simbologia das funções da personagem 
animal, a vaca, pois revela um aspecto fundamental sobre o papel imposto à mulher nas sociedades de classes: a fêmea silenciosa fêmea nutriz e servindo à sua reprodução, premida a se constituir no sustentáculo de uma família no espaço do lar e no tempo das gerações.

Ao longo da história, João troca a vaca por três feijões mágicos devido à distração, em virtude de sua ganância e, por um momento, não avalia o valor da vaca, mas ao chegar a casa, sua mãe chama sua atenção para o mal negócio. Ela, por ter utilizado do leite para industriar os produtos lácteos, alimentar-se deles e os industriar, reconhece concretamente o real valor da vaca, em relação a três feijões - um sonho de riqueza e uma promessa.

Nesse momento, percebemos um corte no enredo, como se iniciasse outra história, pois a partir do crescimento do pé de feijão, o autor (por meio de seu protagonista) se afasta da dura realidade de pobreza daquela família, e introduz na narrativa, elementos fantásticos. Agora, Viana (2017) conduz o leitor ao mundo das árvores mágicas, gigantes, harpas falantes, fadas, galinhas dos ovos de ouro um espaço distinto do chão, da realidade, muitas vezes retratados por diversos ilustradores como além das nuvens.

Quanto aos personagens masculinos, quase todos são figuras humanas: João, Jesuíno, o homem feio e barbudo e o Gigante. Os homens circulam entre a vida pública e a privada, e as mulheres são retratadas, predominantemente, em ambientes domésticos, onde conciliam múltiplas jornadas, relacionadas à reprodução familiar, como alimentação, limpeza, e à sustentação econômica da família, nessa ambientação rural, onde as tarefas referentes ao trabalho produtivo e à reprodução da vida doméstica se entrelaçam, pois a produção de alimentos para comercialização constitui-se numa extensão da produção para o consumo familiar.

Tanto na família composta pela mãe e João, quanto na composta pelo casal de gigantes, trata-se de uma ambientação rural e, ali, a família é o que Saffioti (2013) destaca como a unidade produtiva. Portanto, a exploração do trabalho é uma constante em todas as personagens femininas, mesmo no universo maravilhoso, pois a galinha dos ovos de ouro e a rabeca mágica estão a serviço do Gigante.

A alimentação e a proteção provida pelas mulheres são apresentadas como atividades virtuosas, afirmativas desse duplo papel atribuído às muIheres. $\mathrm{E}$ tais atributos podem levar as leitoras e leitores a construírem uma imagem feminina congruente com visões sexistas e hierarquizadas, não só no âmbito doméstico, como nos diferentes ambientes sociais, conforme observamos no diálogo entre o casal de gigantes: "Meu velho, são as sobras do jantar. Lembre-se de que à noite comeste pra se fartar, agora vá para mesa, seu prato, eu vou preparar" (VIANA, 2017, p. 18). 
As personagens femininas aparecem, ainda em obrigações diversas e naturalizantes da divisão sexual do trabalho doméstico, como a arrumação da casa e os cuidados com a horta. Elas assumem uma postura servil, tanto perante o Gigante, quanto em relação ao próprio invasor, João, a quem a Giganta alimenta e protege, apesar de ele ser ladrão de objetos de sua família. Enfim, a Giganta é apresentada como bondosa e ingênua - características atribuídas à mulher, no âmbito do senso comum:"Mas quando ele foi chegando, Veio ali cumprimentá-lo uma bondosa giganta, que parecia esperá-lo. O conduziu pra cozinha na intenção de alimentá-lo" (VIANA, 2017, p. 16).

A Giganta, ao tomar a iniciativa de alimentar e proteger o protagonista faz um esforço para ele manter sua integridade física, a partir da consciência da violência do seu marido. Ratifica-se, assim, a imagem de mulher nutriz e protetora perante a vulnerabilidade do protagonista: "E logo pediu a ela algo para merendar. Ela então disse pra ele: - Coma e trate de marchar! Pois, se meu marido o vir, ele vai te devorar!" (VIANA, 2017, p. 20).

Quanto às relações de poder, destacamos as manifestações autoritárias de mando do Gigante, indicativas da sua postura opressiva, expressando uma hierarquia entre homens e mulheres, enfatizada por elementos como "depressa", "preciso" no trecho: "- Vá bem depressa ao poleiro e traga minha galinha, pois preciso de dinheiro! A mulher trouxe a galinha e o gigante ordenou: - Eu quero um ovo de ouro! E a tal galinha botou [...]" (VIANA, 2017, p. 20, grifos nossos).

A quarta figura feminina representada no livro foi a da esposa de João, caracterizada, assim como a fada, tão somente uma bela mulher: "Joãozinho com sua mãe Foi curtir sua riqueza. Casou-se com uma moça que é deusa da beleza [...]" (VIANA, 2017, p. 26).

A mãe é a única personagem feminina descrita sob uma forma equilibrada entre a submissão e o exercício de algum poder, em todo o texto. Inicialmente, ela é identificada como provedora do lar, ao lado do filho, e participante das decisões familiares. Em seguida, ela se decepciona com ele, mediante uma negociação malfeita, a despeito de suas orientações. Nesse momento único, aparece uma mulher questionando um homem diretamente, sem subterfúgios. Porém, em seguida, o leitor é levado a considerar que ela estaria equivocada ao criticar o filho e ao desconfiar do potencial dos feijões, pois eles cresceram, levaram ao gigante e, ao final, eles se tornaram ricos, sugerindo a ideia de deslegitimação das ponderações da mãe. Contudo, do ponto de vista objetivo, a troca de uma vaca, por alguns feijões, foi, de fato, desvantajosa, no âmbito imediato.

Mediante as peripécias do filho, essa mãe aparece chorando, abraçando-o, implorando, receosa por ele; porém, impotente para intervir em suas incursões à casa do gigante. 
Embora, na caracterização inicial, a mãe apareça com atribuições de tarefas domésticas, quem aparece em ação é a Giganta, pois, apesar de suas dimensões físicas enormes, é servil, tanto nas relações com o Gigante, quanto as de João. No âmbito dessa servidão, ela trabalha, cultiva, protege e alimenta.

Apesar de em nenhum momento enfrentar os personagens masculinos, a Giganta participa de ardis para controlar as ações do Gigante e até mesmo para enganá-lo. De qualquer forma, tanto a Giganta, quanto a mãe de João são retratadas na condição de exploradas permanentemente, no continuum entre trabaIhadoras na confecção de produtos, seja da horta, seja do leite, e ora no trabalho doméstico, socialmente invisibilizado, conforme discutimos anteriormente.

Avaliamos a impossibilidade de o autor permanecer fiel ao conto sem a reprodução das abordagens sexistas e hierarquizadas da mulher, pois isso traria uma ruptura com a obra em questão em relação à original. Mas, na ausência de uma análise crítica, por professoras e professores, ou em decorrência de uma leitura solitária, pela criança, sem a mediação de um adulto questionador da forma como a mulher foi retratada no conto, ele é propício a uma apropriação naturalizada da exploração e a opressão à mulher.

Embora tenhamos optado por apreciar mais detidamente os aspectos referentes ao trabalho feminino, pensamos não ser possível fazê-lo sem a identificação da ideologia machista produtora de hierarquias entre homens e mulheres e legitimam relações opressivas. Essa ideologia serve de justificativas para a divisão sexual do trabalho doméstico, bem como para a exploração diferenciada do trabalho feminino, destacando-se como os aspectos mais marcantes do conto, nas quais personagens aparecem na participação do provimento familiar, na condição de exploradas e oprimidas.

\section{As faces do sexismo em Nossa rua tem um problema}

O livro Nossa rua tem um problema (AZEVEDO, 2017) pertence ao acervo destinado ao terceiro ano do Ensino Fundamental para crianças de oito a nove anos de idade. Ricardo Azevedo publicou sua primeira edição em 1986, pela Edições Paulinas. Analisamos a edição adaptada de 2017.

O livro foi escrito na forma de dois diários: um iniciado após a capa e o outro de trás para frente, iniciando-se a leitura após a contracapa. O enredo consiste em relatos de dias não sequenciais e concomitantes. Um diário é o da menina Clarabel e o outro do menino Zuza, moradores da mesma rua.

O texto dá indícios claros sobre o pertencimento de Clarabel a uma família de classe média, enquanto Zuza, a uma família de classe popular. Ambos os diários iniciam com a frase Nossa rua tem um problema. Para Clarabel, o problema é o conjunto das atividades cotidianas de uma turma de meninos 
na rua e, para Zuza, as sabotagens das meninas às brincadeiras dos meninos e o fato de o irmão de Clarabel, Chico, ser proibido pela família de integrar-se às atividades da turma de meninos da rua. $\mathrm{O}$ autor preservou a linguagem infanto-juvenil em primeira pessoa.

Silvestre (2009) identificou no texto uma diminuição das diferenças entre os relatos no percurso do início ao fim de cada diário e interpretou como indício da intenção do autor de provocar o debate sobre a superação dos sexismos.

Entretanto, em nossa leitura, identificamos tratar-se de duas histórias diferentes, coetâneas acontecendo num cenário e com personagens comuns, porém enredos diferentes, havendo um entrelaçamento delas. Cada diário oferece informações complementares para a compreensão na narrativa do outro, reciprocamente. Tal característica do texto é bastante interessante para a exploração de noções de tempo, espaço e outras que colaborem para o desenvolvimento dos pré-requisitos para o letramento infantil, como as sequencias lógicas.

Nos dois diários são mencionados 23 personagens masculinos adultos e 10 crianças. Todos os homens trabalham fora de casa. Destaque-se o personagem masculino o mendigo Zé Cheiroso, cuja história não é identificada no enredo, mas aponta a presença de um trabalhador em situação de exclusão social. Alguns homens são caracterizados pelos meninos como mal-humorados, temíveis, como Sr. Jurandir, (pai de Clarabel e Chico) e o pai de Dudu, outros como bem-humorados, como Sr. Luís (pai de Bruna, Mauro e Rodolfo) e o Tio Samuca (parente de Beto). A maioria desses personagens adultos masculinos é citada na história apenas uma vez.

Em seu diário, Zuza observa esses homens e captura alguns traços de característicos que, no senso comum, atribui-se ao universo masculino, como a valentia, o vocabulário chulo e a liberdade de fazerem piadas e brincadeiras, o porte atlético, o trabalho com segurança. Assim, ele menciona a braveza do Sr. Jurandir e do pai de Dudu; o fato de Fritz possuir um papagaio a quem ensinava palavras vulgares; o humor do tio Samuca (parente de Beto), o fato de o Sr. Jurandir fazer cooper; o costume do guarda-noturno Frazão de dormir em serviço.

Zuza se refere a duas personagens femininas em seu diário: Clarabel, caracterizada por ele como "chata" e delatora, e uma personagem chamada Dona Odete, uma senhora cuidadora de um cão "como se fosse gente". Dentre os meninos mencionados no diário de Zuza, somente Dudu e os filhos de Dona Leonor não estão em ação, os demais são retratados em brincadeiras livres nas ruas, fazendo traquinagens, proferindo expressões chulas, com conflitos entre si e em brincadeiras comumente atribuídas aos meninos: futebol, polícia e ladrão, pipa, jogo de pingue-pongue, carrinho de rolimã e confecção de barquinhos de papel.

O diário de Clarabel menciona sete mulheres adultas e cinco crianças. 
Dentre as adultas, três não aparecem em ação: a vó de Clarabel, a tia Leonor e a tia Regina. A mãe de Clarabel aparece em cuidados e preocupações com os filhos, compartilhados com o marido; Dona Julieta, em cuidados com os 15 gatos. Somente Dona Maria da Luz é representada como trabalhadora doméstica.

Quanto às brincadeiras, Clarabel registra em seu diário duas ocasiões, nas quais brincou de casinha: a primeira com Dina (irmã de Zé Luís), de patroa e empregada; e a segunda com Adriana, de cuidar da tartaruga; um jogo de batalha naval e, no final do diário, a participação no jogo vôlei, pois futebol ela achava um jogo que ocasionava agressões e roupa sujas (AZEVEDO, 2017). Silvestre $(2009$, p. 3$)$ interpreta a inserção da brincadeira de empregada e patroa entre Clarabel e Dina como intencional, pois "A narrativa trabalha as diferenças individuais e sociais, quando a tendência é generalizar, simplificar e estereotipar os seres, pensamentos e atitudes. A construção literária não omite problemas e diferenças comuns da vida contemporânea".

A segunda situação é aquela apresentada no livro, por uma ilustração da personagem Dona Maria da Luz, a empregada doméstica - única personagem feminina em trabalho remunerado, numa cozinha, com avental e um prato na mão. Porém essa questão não é explorada no texto.

Ao ler os diários, fica clara a representação da família "tradicional" brasileira branca, heteronormativa, de classe média, com pai, mãe, filhos, em que o pai sai para trabalhar, a mãe fica em casa e os filhos vão à escola e brincam, reproduzindo-se um padrão de família nuclear e de pessoas de idade morando sozinhas com animais de estimação. Assim, não identificamos a inserção de questionamentos sobre questões sociais produtoras de relativização desse modelo familiar no enredo, apesar de a realidade social, hoje ser bem mais complexa.

Quanto à questão das profissões, conforme o discutido anteriormente, as mulheres relacionam-se socialmente com o trabalho no capitalismo, num continuum de diferentes condições, as quais perpassam do trabalho doméstico para a reprodução familiar, geração de renda e da atividade informal até a formal, a qual por vezes, com instabilidades contratuais e falta de isonomia salarial, na carreira e nos cargos, justificada pela própria condição feminina.

A trabalhadora doméstica, embora exerça uma profissão antiga, teve seus direitos reconhecidos no Brasil, na década de 1970, mas regulamentados e ampliados apenas no ano de 2013, e em 2015, com a PEC 150, transformada em lei em junho do mesmo ano, quando vieram a ter mais benefícios, como: seguro, FGTS e multas por dispensa injustificada. Houve, ainda, a redução da alíquota paga pelo empregador, relativa ao INSS, anteriormente de $12 \%$, passando para $8 \%$.

$\mathrm{O}$ trabalho doméstico passou a ter a regulamentação da jornada de 44 horas semanais e critérios específicos para os trabalhadores atuantes em jornada parcial. A contratação de pessoas menores de 18 anos para desempenhar 
atividades domésticas foi vetada (RETROSPECTIVA [...], 2016, n.p.). Assim, até bem recentemente, o trabalho doméstico ainda era regido por contratos muitas vezes verbais, o que se assemelha às relações próximas da escravocracia.

Enfim, trata-se de uma obra que valoriza um modelo de família nuclear, a qual há uma divisão sexual do trabalho e das brincadeiras entre meninas e meninos, bem como destaca a mulher no papel de protetora e cuidadora, como sua característica principal naturalizada. Ademais, as mulheres do enredo posicionam-se primordialmente no ambiente doméstico, enquanto os homens usufruem dos ambientes públicos.

\section{A mulher como sujeito social - As mil e uma histórias de Manoela}

O livro As mil e uma histórias de Manoela é uma obra pertencente ao acervo destinado às crianças do terceiro ano do Ensino Fundamental. Marcelo Maluf publicou sua primeira edição em 2013, pela "Autêntica Editora Ltda", sendo Weber Sampaio o ilustrador da obra.

A se obra desenvolve em linguagem textual, mas as ilustrações complementam as informações sobre a história. Manuela tem sete anos e iniciou a aventura pelos livros na biblioteca do avô e na escola. A palavra ler foi substituída por devorar e comer, numa analogia entre os prazeres de ler e os de se nutrir.

A protagonista é apresentada sob os cuidados do avô - um homem. $\mathrm{Na}$ história, mencionaram-se os títulos das obras lidas por ela, os quais dizem respeito a protagonistas femininas, como As reinações de Narizinho e Alice no país das maravilhas. Ambas as protagonistas - Narizinho e Alice - rompem com o mundo real nas suas próprias histórias. A primeira vai para o Reino das Águas Claras e a segunda, para o País das Maravilhas. Com coragem, elas vivem muitas aventuras e conhecem coisas novas, fazem novos amigos, constituindo-se no próprio sentido de crescer, superar a infância e se aventurar pelos novos mundos apresentados pela escola e por tantas outras oportunidades propostas pela vida. Então, o livro em estudo sugere conecções com outras obras cuja presença feminina assume uma perspectiva da mulher livre.

Do ponto de vista imediato, ao intitularem as obras consumidas pela protagonista suscitam a curiosidade pelas obras. Salientamos que As reinações de Narizinho - de Monteiro Lobato é marco da literatura destinada às crianças, no Brasil - por conter, em seus enredos, problemas sociais, políticas e culturais (COELHO, 1995); e Alice no país das maravilhas é um excelente exemplo de obra literária fantástico-maravilhosa, afamada pela mistura realidade com fantasia e retrata a aventura de uma menina por um mundo novo, o qual Ihe disponibiliza novos aprendizados (COELHO, 1995). Tais referências 
enriquecem ainda mais o texto em análise.

Outra possibilidade de trabalho com o livro em análise é a da transformação de leitores em autores, cujo processo envolve a imersão (comer livros, saborear estilos); identificar-se nas histórias (transformar-se em livro), transformar-se no autor (consumir-se, digerir a vida, a relação com a natureza e outros). Retrata-se o processo de transformação intelectual de leitoras e leitores em autoras e autores, num contexto de produção, nos campos da Ciência, da Arte, da Tecnologia e do pensamento ainda é dominada pelos homens. Manuela aprendeu nos livros a construir-se, mas, também, escrever e "existir no mundo" (MALUF, 2013).

Manuela iniciou sua jornada de leitora com os livros da biblioteca de seu avô; porém, quando eles acabaram, ela começou a ler os da escola. No corpo do texto, o autor descreve uma cena a qual faz um jogo de palavras para ratificar a ideia de associação entre o prazer da alimentação do corpo físico e o da leitura, ao apresentar a escolha da menina de um livro ao chocolate:

Ele tinha tentado trocar livros por chocolate. -- MAS, VOVÔ - a menina dizia -, Nenhum chocolate é melhor que um livro de poesia! Nem os amargos! E O AVÔ, que era um grande leitor, pensava: "não é que a minha neta é mesmo esperta?!" (MALUF, 2013, p. 10-11).

Manuela é uma criança, portanto, carente de cuidados providos pela figura masculina do avô, neste caso, mas se destaca na cena, também, o compartilhamento com seu avô do prazer de ler e de escrever (MALUF, 2013). Por isso, o ilustrador teve o cuidado de retratar o avô e Manuela em atividade de leitura, reiterando o texto escrito e nos levando à incursão na ludicidade da obra (RAMOS; PANOZZO, 2004).

Enfim, o livro apresenta às crianças não só a dimensão prazerosa da leitura, mas também a da escrita, tornando-se especial pelo fato de ele retratar o processo de transformação intelectual de leitora em autora, processo este protagonizado por uma menina.

\footnotetext{
E QUANTO MAIS Manuela escrevia, mais as páginas que estavam grudadas em sua pele iam encolhendo e desaparecendo dela. ATÉ QUE SUMIRAM. QUANDO COLOCOU o ponto final na história, Manuela percebeu que havia escrito o seu primeiro livro, e que ele era resultado dos inúmeros livros que havia comido - mas, ao mesmo tempo, não era nenhum deles. (MALUF, 2013, p. 25-26).
}

O livro As mil e uma histórias de Manuela corrobora com as nossas discussões quanto ao fato de ele ter um potencial formador e de combate a ideologias. Além disso, a obra, no plano imediato, apresenta-se de maneira lúdica, mas também se revela como uma peça literária complexa, a qual trata de temáticas abstratas e desafiadoras para o trabalho escolar a ser desenvolvido 
pelas professoras e professores. A relação de Manuela com os livros indica uma relação das crianças com o conhecimento e, dentro desse processo, a importância de um mediador adulto.

Enfim, apesar de tantas conquistas, vivemos num contexto no qual as mulheres ainda enfrentam o machismo como um obstáculo importante para a ampliação de sua participação na vida pública, na ciência, no desenvolvimento científico e tecnológico, bem como no mercado de trabalho. Elas ainda são invisibilizadas perante o Estado e suas instituições sociais:

\begin{abstract}
Quanto à participação feminina na produção do conhecimento, o primeiro ponto a ser ressaltado é a ausência de preocupação dos órgãos oficiais que coordenam o sistema de CT\&I no Brasil em desvelar a presença feminina neste sistema. Como os estudiosos da questão de gênero não cansam de alertar, somente o olhar interessado de pesquisadores envolvidos com a questão pode encontrar a mulher onde as estatísticas insistem em tratar os diferentes como iguais. Isso acontece, a despeito do crescente consenso de que a perspectiva de gênero contribui positivamente para apontar as falhas na distribuição dos papéis sociais (MELLO et al., 2005, p. 1)
\end{abstract}

As obras como essa, cuja protagonista é uma menina leitora, "devoradora" de livros, que "se transforma" em livros e produtora de livros, constituem-se num instrumento fundamental para a educação contra a supremacia masculina.

\title{
Considerações finais
}

A escola capitalista, ao mesmo tempo em que reproduz a contradição na qual o trabalho é a categoria central fundante da humanização do homem e fator de alienação, constitui-se num espaço de reprodução e superação da opressão e da exploração, durante o desenvolvimento dos alunos, no ensino básico. Apesar desses limites, a escola capitalista, ao formar a classe trabalhadora, pode ser apropriada pelos professores para formação integral dos seres humanos, com o aporte de instrumentos valiosos como as obras literárias, desde que submetidas a uma escolha rigorosa por professores e gestores.

O neoliberalismo tem fomentado propostas de inclusão social dos oprimidos, envolvendo o espaço escolar, como recurso para a superação dos preconceitos e intolerâncias na sociedade. Desde então, são anunciadas políticas inclusivas no Brasil, para dar combate ao racismo, à homofobia, não sem resistências dos setores mais conservadores da sociedade. Isso tem motivado polêmicas tanto nos debates, nas estruturas dos poderes legislativo, executivo e judiciário, quanto na sociedade civil. Porém, as políticas reais de combate à opressão machista nas escolas são incipientes. Na Constituição Federal de 1988, há a exortação à redução da desigualdade de gêneros como essencial 
para a construção de uma sociedade livre, justa e solidária, reproduzida nos planos nacionais de políticas para mulheres, no período de 2006 a 2013. Entretanto, o debate sobre igualdade de direitos no âmbito das especificidades das mulheres ainda não faz parte nem das bases comuns curriculares, nem dos documentos oficiais orientadores dos currículos. Talvez esse seja o motivo da raridade de obras de literatura para crianças que tematizam o trabalho feminino.

Do presente estudo depreendemos que, para além do problema da raridade de obras infantis dedicadas a apresentar a mulher moderna, trabaIhadora, em igualdade de direitos e deveres com os homens, livres de desvios sexistas, as obras literárias para o público infantil não escapam às pressões culturais de uma sociedade de classes, trabalho alienado e reprodução da divisão sexual do trabalho, da exploração e opressão das mulheres.

Ao analisarmos o conteúdo de três obras oferecidas no PNAIC, constatamos diferentes aspectos da divisão sexual do trabalho, especialmente no texto João e o pé de feijão e Minha rua tem um problema, cuja característica não desqualifica as outras virtudes deles, mas chama a atenção para seus limites no combate ao machismo desde a escola.

Enquanto no primeiro livro as mulheres aparecem na cena rural, como produtoras, em atividades de cuidado e proteção, choro e lamento - mas também de dissimulação e enfrentamento como formas de afirmar sua existência - no segundo, elas aparecem na cena urbana, inseridas em famílias assalariadas. No universo privado não se faz menção à participação no provento familiar, e com ênfase numa divisão sexual dos costumes entre homens e mulheres desde a infância. A única mulher que trabalha fora de casa é a doméstica - uma prestadora de serviços em outro lar, mas cumprindo as mesmas tarefas atribuídas como "serviço de mulher".

O terceiro livro inicia-se apresentando um homem, que não é o pai, em cuidados com a neta, cuja cena, além de remeter as crianças - especialmente as filhas de mulheres trabalhadoras - a suas realidades de serem cuidadas por avós ou outros membros da família, também apresenta a possibilidade de que os cuidados não sejam tarefa exclusiva feminina. Porém, o foco da obra é o movimento da menina em seu percurso intelectual. Trata-se de um texto, cuja riqueza pode ser apreendida e objetivada para discussões com as crianças em dois níveis de profundidade: a primeira, mais específica, é o processo de transformação do leitor em escritor, adequada para crianças menores; a discussão mais profunda a partir do texto consiste na reflexão sobre o próprio crescimento e desenvolvimento da criança, numa perspectiva filosófica sobre a dialética da superação com incorporação da fase infantil, para crianças em idade mais próxima da puberdade, incluindo-se, também, o recorte de gênero.

As obras infantis reprodutoras de padrões de comportamento supre- 
macistas masculinos fixam a mulher no papel social de cuidadora e protetora, reclusa ao ambiente doméstico, que não corresponde à realidade das mulheres trabalhadoras no modo de produção capitalista e as que saúdam a mulher moderna, "empoderada" subsomem a dramática multiplicação de tarefas. A identificação de tal problemática coloca aos professores e gestores o desafio de conduzirem aos pequenos leitores livros promotoras de relações humanas livres de exploração e preconceito, elementos fundamentais e indissociáveis para a leitura prazerosa, fundada numa ética e uma estética superior: a beleza de crescer se reconhecendo parte do mesmo gênero humano.

\section{Referências}

ABRANTES, Ângelo Antonio. A educação escolar e a promoção do desenvolvimento do pensamento: a mediação da literatura infantil. 2011, Tese (Doutorado em Educação) - Faculdade de Educação, Universidade Estadual de Campinas, Campinas, 2011.

ARGÜELO, Zandra Elisa. Dialogando com crianças sobre gênero através da literatura. Dissertação (Mestrado em Educação) - Faculdade de Educação, Universidade Federal do Rio Grande do Sul. Porto Alegre, 2005.

AZEVEDO, Ricardo José Duff. Nossa rua tem um problema. São Paulo: Somos Educação SA Brasileiro, 2017.

BRASIL. Secretaria de Educação Básica. Diretoria de Apoio à Gestão Educacional. Pacto Nacional pela Alfabetização na Idade Certa. Documento Orientador. Ministério da Educação, Secretaria de Educação Básica, Diretoria de Apoio à Gestão Educacional. - Brasília: MEC, SEB, 2017. Disponível em: http://pacto.mec.gov.br/images/pdf/doc_orientador/doc_orientador_ versao_final.pdf Acesso em: 1 abr. 2019.

CANDIDO, Antonio. O direito à literatura. In: CANDIDO, A. Vários escritos. 5. ed. (rev.) Rio de Janeiro: Ouro sobre azul, 2011.

COELHO, Nelly Novaes; Panorama histórico da literatura infantil juvenil. $13^{\circ}$. Ed. São Paulo: Quíron, 1985.

ENGELS, Frederick. A origem da família, da propriedade privada e do Estado. 3. ed. Rio de Janeiro: Civilização brasileira, 1977. 
FORTUNATO, Inês Raquel Oliveira. Representações de género na literatura para crianças: percepções das crianças do ensino pré-escolar. Dissertação (Mestrado em Educação Pré-Escolar e Ensino do $1^{\circ}$ Ciclo do Ensino Básico) Escola Superior de Educação Orgânica/ Instituto Politécnico Castelo Branco. Portugal, 2015.

HIRATA, Helena Nova divisão sexual do trabalho? um olhar voltado para a empresa e a sociedade. 1. ed. 1. reimpr. São Paulo: Boitempo editorial, 2012.

JANH, Lívia Petry A literatura de cordel no século XXI: novas e velhas linguagens na obra de Klévisson Viana. Dissertação (Mestrado em Letras) Instituto de Letras, Universidade Federal do Rio Grande do Sul, Porto Alegre, 2011.

JELIN, Elizabeth. Mulheres e direitos humanos. Estudos Feministas, Florianópolis -SC, n. 1, p. 117-149, 1994.

LIMA, Jaqueline Moreira Ferraz de. "Serviço de Mulher": a mulher e a educação para o trabalho, sob a mediação da literatura infantil. Dissertação (Mestrado em Educação) - Instituto de Biociências, Universidade Estadual Paulista, Rio Claro-SP, 2019,

MALUF, Marcelo. As mil e uma histórias de Manuela. São Paulo: Autêntica Editora Ltda, 2013.

MELLO, H. P.; LASTRES, H. M. M.; MARQUES, T. C. N. Gênero, ciência, tecnologia e inovação no Brasil. Revista Gênero, Rio de Janeiro, v. 1, n. 2, p. 73-94, 2004. Disponível em: https://periodicos.uff.br/revistagenero/article/view/31033. Acesso em: 29 jul. 2020.

MONTEIRO, A. O que é inovação social? Maleabilidade conceitual e implicações práticas. Dados, Rio de Janeiro, v. 62, n. 3, p. 1-34, 2019. Disponível em https://www.scielo.br/scielo.php?script=sci arttext\&pid=S0011-52582019000300201. Acesso em: 29 jul. 2020.

MORTATTI, Maria do Rosário Longo. Na história do ensino da literatura no Brasil: problemas e possibilidades para o século XXI. Educar em Revista, Curitiba, n. 52, p. 23-43, abr./jun. 2014. Disponível em: https://revistas.ufpr. br/educar/article/view/36317. Acesso em: 01 de abr. de 2019.

RAMALHO, Christina. Mulheres, princesas e fadas: a hora da desconstrução. 
Gênero, Niterói, v. 1, n. 2, p. 41-48, 2001. Disponível em: https://periodicos.uff. br/revistagenero/article/view/31117. Acesso em: 1 abr. 2019.

RAMOS, Flávia Brocchetto; PANOZZO, Neiva Senaide Petry. Entre a ilustração e a palavra: buscando pontos de ancoragem. Espetáculo. Revista de estúdios literários, Madrid, n. 26, p. 1-12, 2004. Disponível em: http://webs.ucm.es/ info/especulo/numero26/ima_infa.html. Acesso em: 10 ago. 2019.

RETROSPECTIVA Doméstica Legal sobre primeiro ano da Lei Complementar 150: $\mathrm{O}$ que mudou nos direitos dos empregados e na rotina dos empregadores no primeiro ano de vigor da lei que prevê condições igualitárias para trabalhadores domésticos. 03 de jun. de 2016. Disponível em: https://www. domesticalegal.com.br/retrospectiva-domestica-legal-sobre-1-ano-da-leicomplementar-150/. Acesso em: 13 out. 2019.

SAFFIOTI, Heleieth A mulher na sociedade de classes: mito e realidade. 3. ed. São Paulo: Expressão popular, 2013.

SILVESTRE, Penha Lucilda de Souza. Uma leitura da obra "Nossa rua tem um problema", de Ricardo Azevedo. In: 14 CONGRESSO DE LEITURA DO BRASIL, 2003, Campinas. Disponível em: http://alb.org.br/arquivo-morto/edicoes_ anteriores/anais14/Sem09/C09051.doc. Acesso em: 8 out. 2019.

VIANA, Klevisson. João e o pé de feijão. Fortaleza: Fundação Demócrito Rocha Brasileira, 2017.

Recebido em: 2 de fevereiro de 2021.

Aprovado em: 30 de maio de 2021. 
